\title{
Histopathologic Impacts of Diabetes Mellitus on Umbilical Cord During Pregnancy
}

\author{
Bahiru Tenaw Goshu (D) \\ Department of Human Anatomy, College \\ of Medicine and Health Sciences, \\ University of Gondar, Gondar, Ethiopia
}

\begin{abstract}
As a feto-maternal connection route, the umbilical cord is an important determinant of fetal well-being. The umbilical vessels, unlike major vessels, are not fed by the vasa vasorum, making them more vulnerable to hemodynamic changes induced by maternal diseases such as diabetes mellitus. Furthermore, it may be discarded for exacerbating any perinatal illness. The umbilical cord is the major supporter of a successful neonatal prognosis, since it is the sole organ that initiates life. It plays the most important role in fetoplacental relation, as well as what will happen to the infant on extra-uterine life. As a result, the histopathologic alterations in the umbilical cord associated with gestational diabetes mellitus were examined in this review study.
\end{abstract}

Keywords: histopathology, umbilical cord, gestational diabetes mellitus

\section{Background}

The umbilical cord, which is a coiled structure that connects the fetus to the placenta, is essential for the embryo's and fetus' growth. It includes Wharton jelly, two umbilical arteries, and one umbilical vein. Wharton's jelly is a connective tissue that protects the umbilical cord vessels by acting as a cushion. The umbilical cord is around $1.21 \mathrm{~cm}$ in diameter and 50 to $60 \mathrm{~cm}$ long when a baby is born. The umbilical arteries transport blood out of the fetus, while the umbilical vein returns blood and removes waste materials. ${ }^{1,2,4,5}$

The umbilical cord is coated with trodden amniotic epithelial cells on the outside. The yolk stalk and continuation duct run the length of the cord, but the allantoic duct only runs into its proximal half. As the cord matures, different mesenchymal compartments merge and gradually change into Wharton's jelly. ${ }^{6}$

The umbilical cord, as a primary gate of blood to the fetus, is a vital structure for the maintenance of intrauterine life, and its well-being is the main contributor to a favorable newborn prognosis, regardless of any prenatal problems. Therefore the umbilical cord is most often the sole organ present when life begins, it performs the most important role in the feto-placental relationship and in determining what will happen next. Because the outcome of $\mathrm{UC}$ is the conduit between the baby and the placenta, UC and blood vessel morphology is an essential indication of fetal wellbeing. Umbilical arteries are oxygen-dependent because they are not supplied by the vasa vasorum, making them more vulnerable to hemodynamic changes induced by maternal diseases, such as diabetes mellitus. ${ }^{7-9}$

Diabetes mellitus is a metabolic disease that affects the structure of umbilical cord tissue, resulting in aberrant vascularization and, in the long run,
Correspondence: Bahiru Tenaw Goshu Tel +25l 918640145

Email haikutena@gmail.com 
vasculopathy. ${ }^{10}$ Diabetic pregnancies are categorized as either gestational diabetes mellitus (GDM) or pregestational diabetes (PGDM) according to the White classification, with the PGDM group being further split into subgroups according to the presence and/or severity of the condition. $^{11,12}$

GDM is defined as a mother's inability to tolerate carbs of varying intensity after initially recognizing them during pregnancy. It is the most frequent medical pregnancy complication, with a high mother and fetal death and morbidity rate. ${ }^{13}$ The histopathologic examination of GDM revealed fragmentation of the endothelium and a break in the umbilical arteries, resulting in blood extravasation inside Wharton's jelly. Wharton's jelly also undergoes honeycomb-like transformations. Furthermore, the smooth muscles of the umbilical arteries are disrupted, and their fibers degenerate. ${ }^{14,15}$ As a result, GDM may have certain negative effects on the Wharton's jelly's umbilical arteries and connective tissue components.

\section{Methods}

Data from published papers were collected using electronic databases such as PubMed/PMC, Embase Elsevier, and Google Scholar. We included the terms Histology of umbilical cord, histopathology of umbilical cord, impact of gestational diabetes mellitus on umbilical cord, or alternatively, in all relevant articles. As screening techniques, titles and abstracts were used to choose studies. Full-text articles were reviewed and obtained to locate relevant studies. The final articles were weeded out of duplicated works.

\section{Study Selection}

The histopathologic influence of diabetes mellitus on the umbilical cord was given in research publications published in several journals, together with appropriate information on the study technique. Research papers limited the influence of diabetes mellitus on umbilical cord architecture and articles lacking a microscope picture were excluded as exclusion criteria. When a paper was eligible for inclusion, the author had confirmed all the relevant components for accurate documentation.

\section{Quality Assessment}

The author reviewed the pertinent data using a standardized data extraction form for this study.

\section{Microanatomy of Normal Umbilical Cord}

The histology of the umbilical cord's components, an artery, vein, and Wharton's jelly, may be seen in microscopic detail. Amnionic epithelium also protects it. The epithelium around the umbilical cord insertion is mostly non-keratinized, stratified squamous epithelium. The epithelium changes into a stratified columnar epithelium distant from the insertion site, then into a simple columnar epithelium. The latter keeps growing into a simple columnar to the cuboidal epithelium of the placental amnionic surface. Wharton's jelly has a typical distribution of spindle-shaped fibroblasts as well as a large number of mast cells. UC did not have any adventitia, external elastic lamina, or vasa vasorum. Endothelium lined the lumen; unlike other arteries, the umbilical artery lacks an internal elastic membrane and has much less. In contrast, the vein possesses an elastic subintimal layer. The muscular coat of the arteries is made up of a system of spiraling fibers that cross each other. ${ }^{15}$

As demonstrated in Figures 1A and 1B, the lumens of the artery constricted with a branched shape and lined by endothelial cells with prominent nuclei. A well-developed intimal layer with variable thickenings showed thin, elongated, or wavy smooth muscle cells cut in the transverse section. The media of the arteries was thick showing an inner layer of longitudinal smooth muscle cells, poorly differentiated and an outer coat consisting of a system of crossing spiralled smooth muscle cells. The lumen of the vein presented circular or triangular shapes. As compared to the arteries, the intima layer of the vein and the

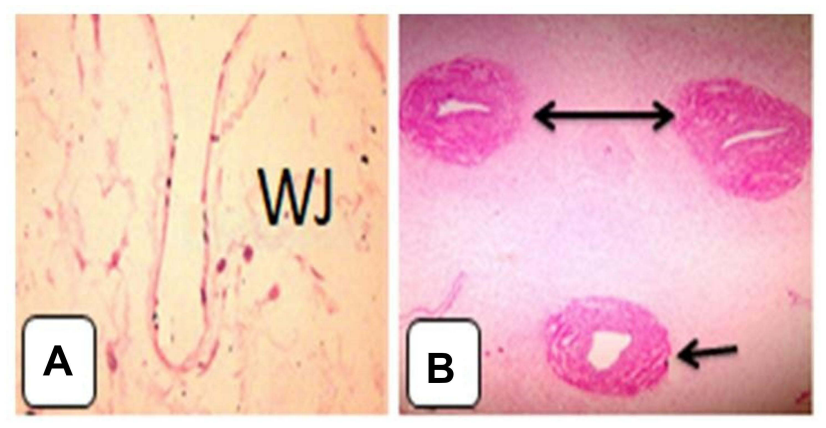

Figure I Cross-section of the mature umbilical cord and schematic representation of mature umbilical cord showing (A) wharton's jelly with artery, (B) one umbilical vein (single headed arrow), and two arteries (double headed arrow) with Wharton's jelly H\&E. 4x.

Notes: Adapted with permission from El-Nefiawy NE. Development of Human Umbilical Vessels in The Second Trimester of Pregnancy: Histological, Immunohistochemical and Morphometric Study. The Egyptian Journal of Histology. 20I7:40(2);226-240. doi: I0.2I608/EJH.20I7.4079. 
muscular coats were thin. Wharton's jelly consisted of a mucoid structure consisting of a ground substance of mucopolysaccharides. ${ }^{4,16-18}$

\section{Histopathologic Impacts of GDM in Umbilical Cord}

As it is revealed in Figure 2A, gestational diabetes mellitus had an impact on the umbilical cord crack and disintegration of the endothelium and crack of the umbilical vessels coming about in extravasation of blood inside Wharton's jelly. The umbilical vein was widened and lean-walled. Smooth muscles of the umbilical vessel appeared disturbance and degeneration of its strands. The arteries have constricted lumen in comparison to the control group. The endothelial cells of the intima were discontinuous with focal erosions. The media showed widely separated SMC by connective tissue containing few collagen and elastic fibers with mononuclear cell infiltration. Extravasation of arterial blood to Wharton's jelly was seen. The vein has a thinner wall and wider lumen in comparison to the control group. In addition, there was no adventitia vein of case group. , $^{91,13,15,18}$
The amnion membrane and artery endothelium were histologically normal, but the Wharton's jelly had dilated pores and edema. Wharton's jelly seemed to alter as a result of the degeneration of its fibers, which had honeycomb-like purging gaps. Furthermore, GDM may have certain negative effects on the Wharton's umbilical veins and connective tissue components. The umbilical cord of diabetes group sections stained with H \& E of wharton's jelly indicated that its fibers were disrupted and that large irregular empty areas resembling honeycombs were widely spaced. ${ }^{8,13,14,19-29}$

A similar study found that the wharton's jelly and fibroblast cells are enclosed by amniotic membrane in the histological section of the umbilical cord of the control group, with an umbilical artery of narrow lumen, intima, and thick media with no adventitia and an umbilical vein of wide lumen, thin intima, and thin media. Honey-combs appear in the diabetic group, with a narrow lumen, intima, and thick media with cellular debris, extracellular infiltration, localized erosion of endothelial lining, and an umbilical vein with a thinner wall and larger lumen with cellular debris in media. ${ }^{12,17}$

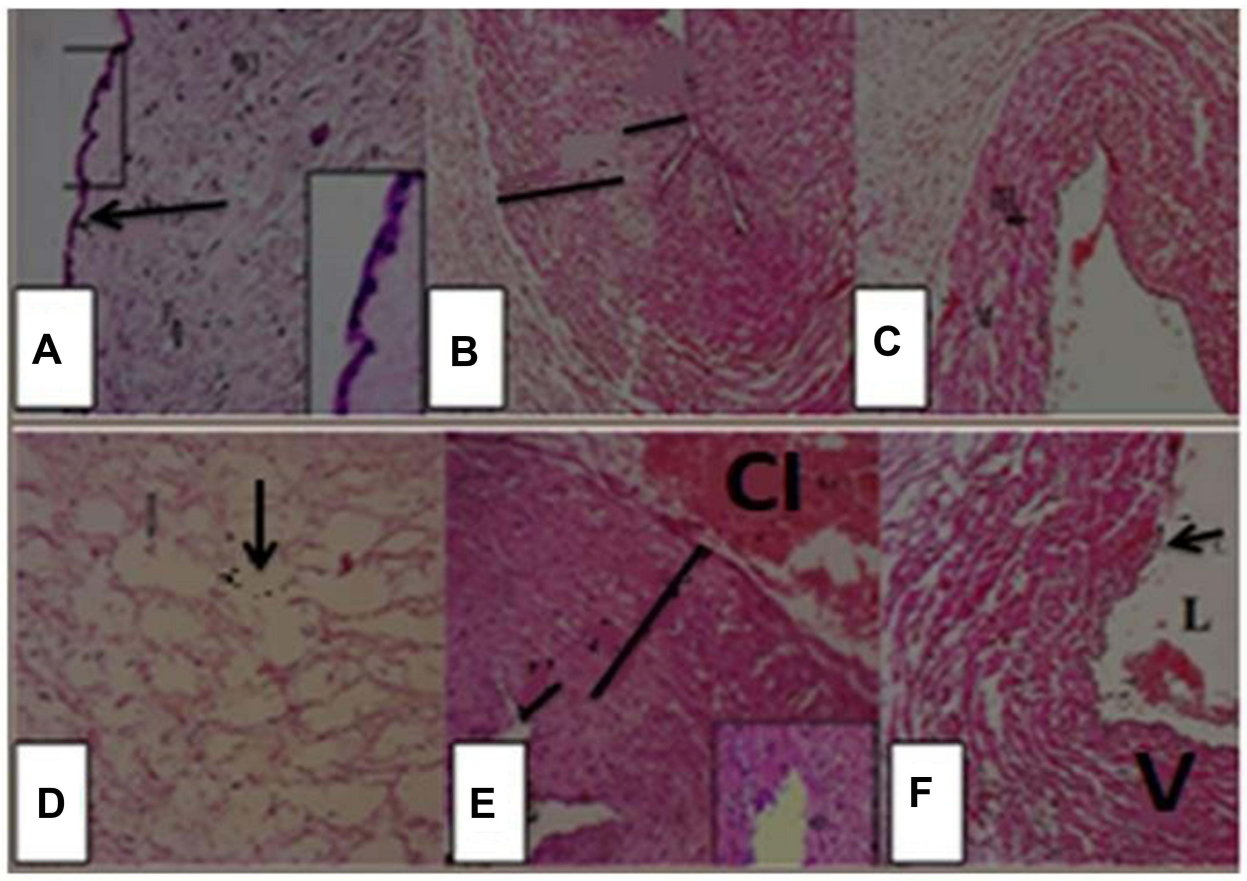

Figure 2 Photomicrographs of umbilical cord sections of control group showing (A) Wharton's jelly, fibroblast cells and enclosed by amniotic membrane (arrow). The inset is higher magnification of the amniotic membrane. (B) Showing part of umbilical artery with lumen (L), intima (short black line) and thick media (long black line) with no adventitia, surrounded by Wharton's jelly (lightly stained). (C) Showing the umbilical vein wide lumen, thin intima and thin media, and surrounded by Wharton's jelly. Umbilical cord sections of diabetic group showing (D) Wharton's jelly, notice honey combs ( $\downarrow$ ). (E) Showing part of umbilical artery (A) with narrow lumen (L), intima (short black line) and thick media with cellular debris (long black line), with extra cellular infiltration (Cl), with focal erosion of endothelial lining. (F) Showing the wall of umbilical vein $(V)$ with thinner wall and wider lumen $(L)$, with cellular debris in media.

Notes: Adapted with permission from Salem MAER, El-Gawwad A, Shadia M, Mahmoud ES, Elyamany HY. Histological study of human umbilical cord in diabetic pregnant females. Egypt J Histol. 2020;42(4):874-887. ${ }^{17}$ Personal non-commercial use only. EJH copyright (C 2019. All rights served. 


\section{Conclusion and Future Directions}

The umbilical artery becomes constricted in the event of diabetes, the endothelial cell of intima becomes discontinuous, and extravasation of arterial blood to wharton's jelly is noted, according to the majority of research. In addition, the vein wall gets thinner and a larger lumen is noticed. As a result of this review, As a result, in order to avoid prenatal complications, According to this review paper, early control and treatment of diabetes mellitus in a pregnant mother is a priority strategy for preventing fetal complications.

\section{Funding}

The author does not receive any grants from any funding agencies.

\section{Disclosure}

The author declares that they have no conflicts of interest in this work.

\section{References}

1. Sharma S, Soliriya V. Study of length of umbilical cord at term and its correlation with fetal outcome: a study of 500 deliveries. J South Asian Feder Obst Gynaecol. 2016;8(3):207-211. doi:10.5005/jp-journals-100061419

2. Liu S, Jia Y, Yuan M, et al. Repair of Osteochondral Defects Using Human Umbilical Cord Wharton's Jelly-Derived Mesenchymal Stem Cells in a Rabbit Model. Biomed Res Int. 2017;2017 Article ID 8760383. doi:10.1155/2017/8760383

3. EI-Nefiawy NE. Development of Human Umbilical Vessels in The Second Trimester of Pregnancy: Histological, Immunohistochemical and Morphometric Study. The Egyptian Journal of Histology. 2017;40 (2);226-240. doi:10.21608/EJH.2017.4079

4. Alam MR, Momen MA, Sultana AA, Hassan SN. Gross and histomorphologic study of the umbilical cord in pre-gestational diabetes mellitus and gestational diabetes mellitus. Bangladesh J Anat. 2014;12 (1):25-29. doi:10.3329/bja.v12i1.22615

5. Standring S. Gray's Anatomy e-Book: The Anatomical Basis of Clinical Practice. Elsevier Health Sciences; 2015.

6. Thomas MR, Bhatia JK, Kumar S, Boruah D. The histology and histomorphometry of umbilical cord cross section in preeclampsia and normal pregnancies: a Comparative Study. J Histotechnol. 2020;43(3):109-117. doi:10.1080/01478885.2020.1734741

7. Kadivar M, Khamseh ME, Malek M, Khajavi A, Noohi AH, Najafi L. Histomorphological changes of the placenta and umbilical cord in pregnancies complicated by gestational diabetes mellitus. Placenta. 2020;97:71-78. doi:10.1016/j.placenta.2020.06.018

8. Salge AKM, Reis MR, Siqueira KM, Castral TC, Guimarães JV, Castro EC. Association between the macroscopic characteristics of the umbilical cord, high-risk pregnancy and neonatal repercussions. Rev Esc Enferm USP. 2018;51:e03294. doi:10.1590/S1980-220X2017006303294.

9. Karaca C, Bostancieri N, Ovayolu A, Kahraman DT. The effect of vascular complications of diabetes mellitus on human umbilical cord tissue and the number of Wharton Jelly's mesenchymal stem cells. Mol Biol Rep. 2020;47(12):9313-9323. doi:10.1007/s11033020-05965-8
10. White P. Classification of obstetric diabetes. Am J Obstet Gynecol. 1978;130(2):228-230. doi:10.1016/0002-9378(78)90373-3

11. Ennazhiyil SV, Ramakrishnan P, Akshara V, et al. Effects of gestational diabetes mellitus on umbilical cord morphology: a Comparative Study. J Clin Diagnostic Res. 2019;13(7).doi: 10.7860/JCDR/2019/40085.12543

12. Cunningham F, Leveno K, Bloom S, Hanth J, Gilstap L, Wenstrom K. The Newborn Infant. Williams Obstetrics. 23rd ed. New York, NY: McGraw-Hill; 2010:590.

13. Aboud F. Histopathological changes of umbilical cord blood vessels in diabetic pregnancies. Tripolitan Med J. 2018;7(2):1-6.

14. Pooransari P, Ebrahimi A, Nazemi N, Yaminifar F, Abediasl Z. Is gross morphology of placenta, umbilical cord, and neonatal outcome in well-controlled gestational diabetes mellitus pregnancy different? A case-control study. Int J Reprod Biomed. 2020;18 (6):407.

15. Jain A, Ranjan R, Jha K. Histomorphometry of umbilical cord in gestational diabetes mellitus. Med Sci. 2014;6(21):71-73.

16. Chakraborty SK, Yousuf BA, Banu LA, Shamim KM. A gross and histomorphological study of the umbilical cord in gestational diabetes mellitus. Bangladesh J Anat. 2011;9(1):21-25. doi:10.3329/bja. v9i1.8143

17. Hershkovitz R, Silberstein T, Sheiner E, et al. Risk factors associated with true knots of the umbilical cord. Eur J Obstet Gynecol Reprod Biol. 2001;98(1):36-39. doi:10.1016/S0301-2115(01)00312-8

18. Salem MAER, El-Gawwad A, Shadia M, Mahmoud ES, Elyamany HY. Histological study of human umbilical cord in diabetic pregnant females. Egypt J Histol. 2020;42(4):874-887. doi:10.21608/ ejh.2019.7717.1076

19. Aboud F, Torjman F, Sultan M, Benjama A. Histopathological Changes of Umbilical Cord Blood Vessels in Diabetic Pregnancies. Tripolitan Medical Journal. 2018;7(2):1-6.

20. Fahmy M. Anatomy of the Umbilical Cord. Umbilicus and Umbilical Cord. Cham: Springer International Publishing; 2018:47-56.

21. Blanco MV, Vega HR, Guerri-Guttenberg RA, et al. Histopathology and histomorphometry of umbilical cord blood vessels. Findings in normal and high risk pregnancies. Artery Res. 2011;5(2):50-57.

22. Bryan EM, Kohler H. The missing umbilical artery: I. Prospective Study based on a maternity unit. Arch Dis Child. 1974;49 (11):844-852. doi:10.1136/adc.49.11.844

23. Koech A, Ndungu P, Gichang P. Structural changes in umbilical vessels in pregnancy induced hypertension. Placenta. 2027;29 (2):210-214. doi:10.1016/j.placenta.2007.10.007

24. Koskinen A, Lehtoranta L, Laiho A, Laine J, Kääpä P, Soukka H. Maternal diabetes induces changes in the umbilical cord gene expression. Placenta. 2015;36(7):767-774. doi:10.1016/j. placenta.2015.04.004

25. Ezimokhai M, Rizk DE, Thomas L. Abnormal vascular coiling of the umbilical cord in gestational diabetes mellitus. Arch Physiol Biochem. 2001;109(3):209-214. doi:10.1076/apab.109.3.209.11593

26. Chitra T, Sushanth YS, Raghavan S. Umbilical coiling index as a marker of perinatal outcome: an Analytical Study. Obstet Gynecol Int. 2012;2012:213689. doi:10.1155/2012/213689

27. Ezimokhai M, Rizk DE, Thomas L. Maternal risk factors for abnormal vascular coiling of the umbilical cord. Am J Perinatol. 2000;17 (8):441-445. doi:10.1055/s-2000-13452

28. Saha S, Biswas S, Mitra D, Adhikari A, Saha C. Histologic and morphometric study of human placenta in gestational diabetes mellitus. Ital J Anat Embryol. 2014;119(1):1-9.

29. Lateef RH. Adverse effects of gestational diabetes mellitus on measurements of the umbilical cord and its vessels. Pak J Biol Sci. 2015;18(7):346. doi:10.3923/pjbs.2015.346.351 


\section{Publish your work in this journal}

Pediatric Health, Medicine and Therapeutics is an international, peerreviewed, open access journal publishing original research, reports, editorials, reviews and commentaries. All aspects of health maintenance, preventative measures and disease treatment interventions are addressed within the journal. Practitioners from all disciplines are invited to submit their work as well as healthcare researchers and patient support groups. The manuscript management system is completely online and includes a very quick and fair peer-review system. Visit http://www.dovepress.com/testimonials.php to read real quotes from published authors. 